\title{
Main topics related to the disease, death, and dying in communication between parents and their adolescent children with incurable cancer
}

\author{
Slaninka $\mathrm{M}^{1}$, Krajmer $\mathrm{P}^{2}$, Kolenova $\mathrm{A}^{2,3}$ \\ Pediatric Hematology and Oncology Clinic, National Institute of Children's Diseases, Bratislava, Slovakia. \\ krajmerpeter@gmail.com
}

\begin{abstract}
OBJECTIVES: The article focuses on main topics related to disease, death, and dying in communication between parents and their adolescent children with this diagnosis.

METHODS: We conducted qualitative research comprising 13 interviews with parents who lost their adolescent child to cancer. We used a semi-structured interview and interpretative phenomenological analysis.

RESULTS: Results introduced 6 basic topics: mutual protection, openness in the communication about cancer and death, making treatment decisions together, talks at the time of passing, hope, and spiritual experience.

CONCLUSION: Adolescents appreciate age-appropriate, open communication about their disease. Talking about the disease and its prognosis appears to be the way from mutual protection to open truthfulness. Openness also includes the participation of adolescents in further treatment. For some parents, it makes sense to constantly protect the child from the fact of death. Caregivers should support discussions about death between parents and their terminally ill adolescent children and accept individual decisions to talk about death (Tab. 1, Ref. 25). Text in PDF www.elis.sk KEY WORDS: cancer, adolescent, parent, terminally ill, communication, qualitative method.
\end{abstract}

\section{Introduction}

Parents indicate that talking about cancer with their child is one of the most significant sources of stress during treatment (Rodriguez et al, 2012). Children experience feelings of sadness, anxiety, and fear of being alone (Cataudella, Zelcer, 2012). Parents may experience fear, depression, stress, anger, and guilt over not being able to protect their child (Geest et al, 2015, Smith et al, 2019, Dilek, Özlem, 2020). Their distress may negatively influence children's emotional state and physical pain levels. Cataudella and Zelcer (2012) state that some parents describe their child's deterioration of self-esteem, drastic mood fluctuation, and frustration stemming from their gradual loss of ability to communicate. Older adolescents say that due to misunderstanding and prejudice against cancer and its treatment, they have lost some of their friends (Palmer et al, 2007). Despite the difficult nature of conversations about this disease, when done compassionately and

${ }^{1}$ Prague College of Psychosocial Studies, Prague, Czech Republic, ${ }^{2}$ Pediatric Hematology and Oncology Clinic, National Institute of Children's Diseases, Bratislava, Slovakia, and ${ }^{3}$ Faculty of Medicine, Comenius University, Bratislava, Slovakia

Address for correspondence: P. Krajmer, $\mathrm{PhD}$, Pediatric Hematology and Oncology Clinic, National Institute of Children's Diseases, Street Limbova 1, SK-833 40 Bratislava, Slovakia. respectfully, this conversation can have important implications for how the adolescent lives through the final amount of time of their life, how they die, and how their family copes (Rosenberg et al, 2016). Parents are very respectful of child's emotions through all the time of cancer (Bogetz et al, 2020).

Open communication between parents and their adolescent child with advanced cancer at the time of diagnosis is predictive of lower adolescent distress one year later (Keim et al, 2017). Rosenberg et al (2016) suggest that most adolescents and parents prefer honest disclosure and this allows appropriate decision making. Adolescents wish to fully participate in making the decision on their further treatment. They wish to be informed about their health, even when the treatment is ineffective and their prospects are bleak (Palmer et al, 2007, Bell et al, 2010).

On the other side, Zelcer et al (2010) found that parents do not want to jeopardize their own hopes and those of their children. Parents have a desire to protect their child from bad news, maintain hope as well as to maintain life as normally as possible (Bally et al, 2014, Cataudella and Zelcer, 2012, Geest et al, 2015, Rosenberg et al, 2016).

Popp et al (2015) studied the psychological state of parents regarding the cancer diagnosis of their child. Their study showed that $44 \%$ of parents cannot cope with their child's diagnosis, regardless of when they are informed. Kars et al (2011) refer that every parent fluctuates between two approaches: letting go while 
emphasizing the acceptance of the loss, and protection. These approaches are defined in the course of life and can easily coexist.

Kreicbergs et al (2004) state that only $34 \%$ of parents talked about death with their terminally ill children. This finding is consistent with the study by Geest et al (2015). They found that $64 \%$ of parents did not discuss the impending death with their child. They identified following reasons: the parents' inability to discuss the impending death, the parents' desire to protect their child, views regarding talking with children, parents' views of child's characteristics, the child's unwillingness to discuss the subject, lack of opportunity to talk or child's disability. Some parents are unable to discuss the subject of death with the child because of lacking the confidence in their ability to convey the message. Some parents perceive their child's shyness and they feel it is inappropriate to talk about death with a terminally ill child.

Geest et al (2015) state that some parents feel that their child knows what is going on, so they do not need to talk about it. Children are often aware of their prognosis and they have a profound, maybe complex comprehension of cancer (Geest et al, 2015, Smith et al, 2019). In the study of Cataudella and Zelcer (2012), the majority of parents felt that their child's awareness of impending death was expressed indirectly (for example: by sharing and giving personal things to the other person). Smith et al. (2019) suggest that children rely on parents for the disclosure of information.

Benefits of the conversation about illness and death are as follows: elimination of child's fear, stronger feeling of closeness in the family, the children can organize their funeral themselves according to their wishes, time to process poor prognosis, greater resilience (Geest et al, 2015, Wiener et al, 2015, Smith et al, 2019, Gerrish and Bailey, 2020). Zelcer et al (2010) suggest that children often guide parents through the process of closure and saying goodbye. Geest et al (2015) state that not discussing the subject of death may be the best possibility for some children. Some parents wish to be better prepared for conversation regarding death. A decision as to whether to talk with the child about death should be tailored based on individual context (Hinds et al, 2005, Geest et al, 2015).

Kars et al (2015) state that parents apply direct and indirect strategies to understand the inner world of their child. Indirect strategy means that the parent does not ask directly about the child's feelings but tries to deduce them from the child's behavior. Many parents in this research realized that asking the child directly is

Tab. 1. Characteristics of the parents and children in this study.

\begin{tabular}{lcc}
\hline & Parents & Children \\
\hline $\mathrm{n}$ & 13 & 8 \\
\hline Gender & 5 & 4 \\
$\quad$ Male & 8 & 4 \\
$\quad$ Female & NA \\
$\quad$ Median age at time of interview/years & $49(35-60)$ & $17(15-20)$ \\
$\quad$ Median age at death/years & NA & \\
\hline Diagnosis & NA & 8 \\
$\quad$ Solid tumor &
\end{tabular}

the most direct and best way to learn what their child is experiencing, however, they were hesitant to initiate such conversation. These feelings appeared especially when the child was unwilling to talk about the topic or when the parents perceived the topic to be potentially hurtful to the child.

Children can ask about their prognosis when talking about their disease. In the case of palliative care, they can even ask about the time they have left. Kars et al (2011) report that at the same time, parents can give their child strength to cope with this situation and to create an atmosphere of togetherness.

Openness, respect, and truthfulness, possibly introduced into the dialogue between parents and their children due to the existence of cancer, can contribute to deepening the experience, closeness, understanding of life, and confirmation of mutual affection (Ljungman et al, 2016, Gerrish, Bailey, 2020).

Finally, it is necessary to note that the child's illness does not progress through identical stages, while the doctors face ambiguity in predictions, and unpredictability of the disease's progress. All these changes also affect the life of all involved and all aspects can contribute to the hope and despair of children and their parents, and as such they affect their mutual communication.

\section{Method}

\section{Aim of the study}

The aim of our study is to explore main topics related to disease, death and dying in communication between parents and their adolescent child with this diagnosis.

Parents were interviewed individually after obtaining an informed consent. The interview took between 1.0 and 2.5 hours. The interviews with parents were conducted in line with the principles of the daseinanalytical inward-understanding method (Růžička, 2011), where the therapist is personally, respectfully, openly, and truthfully engaged in the other person's situation.

\section{Choice and characteristics of the research sample}

We have chosen to use a purposeful selection (Miovský, 2006). This form of selection ensures homogeneity of the sample, which is important for interpretative phenomenological analysis (Smith, Osborn, 2003). The study included only parents whose adolescent children were hospitalized at the Pediatric Hematology and Oncology Clinic and it was known that their child had passed during or after hospitalization. The adolescent children were diagnosed with solid tumors in 8 cases. The sample comprised 13 parents, 8 women and 5 men. The age of adolescent children at the time of their death was between 15 and 20 years (Tab.1). Interviews were conducted within 6 months to 4 years after the child's passing.

\section{Data analyses}

A qualitative approach has been chosen for carrying out and processing the achieved results. For our research purposes we used a semi-structured interview and interpretative phenomenological analysis (IPA) to obtain results (Smith, Osborn, 2003, Smith et al, 2009). This approach consisted of the following stages: (1) reading and re-reading, (2) initial remarks and comments, (3) developing 
emerging topics, (4) finding connections across topics, (5) analysis of another case, (6) finding patterns across cases.

\section{Results}

\section{Mutual protection}

The child and the parent may perceive mutual suffering and pain. Thus, they can protect each other, which may lead to this topic not being opened and remain hidden. Following her discussion with the doctors about exhausting the treatment possibilities, Jana enters the room of her daughter Klára (15y):

"We never said anything to Klára, I came in tears, Klára is not stupid, she knew something was up, and she says: 'Mom, you were crying', and I say 'you know, we were discussing outside in the hallway that someone has horrible results', well a white lie... and then one day she told me: 'Mom, I know I'm going to die', and I said: 'Klára, don't say that, why would you die, we all are going to die eventually'. And she said: 'No, I know I'm going to die', and that's when I told her: 'Stop, what would I do here without you'. I understood only with time that I shouldn't have said that because from that moment onwards she never talked of death. I think she was really protecting me till the last day from the reality of her passing".

Protecting the son can be seen as fully justified. After receiving information about the treatment possibilities being exhausted, the mother of Andrej (18y) says: ", Since the beginning, when they told me that there was no further hope for Andrejko, I was constantly asking myself whether I should tell him at all. If I told him, he would suffer a mental breakdown and maybe even die, he would be mentally broken, would refuse everything and die... And when I supported him mentally, he picked himself up so nicely that the doctors were surprised. He shall enjoy life until the very last moment".

\section{Hope}

Hope is shown to be essential during cancer. Kristína (18y) described it as follows: "Mom, those with osteosarcoma in their nodes, none of them survived. All of them died. And I will be the first to survive!" Martin's (17y) father says: "When we accepted help from other people, we manufactured heart tokens and he wrote on them 'Thank you for giving hope', and this we gave to the people who helped one way or another".

\section{Openness and confidence}

Open communication with parents about the diagnosis may take place from the beginning. Mother of Kristína (18y) gives the following description: "She knew everything-about her disease, about everything. When going to the MRI, she asked: 'Mom, is it bad?' I say: 'Bad, very bad'. And we went to the doctor. And she asked the doctor about her chances. We left the room and she started crying and we embraced. And we stood there in the hallway crying and hugging (crying). And then she told me: 'Mom, I'm not afraid to die. I know where I'll be going', we are all religious, 'but I'm afraid of pain'. And we were crying hard and hugging there in the hallway".
In the era of modern technologies children have means of obtaining information on cancer even if you withhold the severity of their illness. "I kept the first death I experienced at Klára's hospital ward as a secret. It was one of Klára's friends. It weighed heavily on me and I never told her... but thanks to Facebook she found out and that's when I got a good dressing-down, she said 'Mom, you think I'm a little child? Why didn't you tell me?' At that moment we made a deal not to lie anymore, to always tell the truth".

The mother of Martin (17y) says: "I told him everything, or at least the important things. Even that there was no cure, I told him. 'Martin there is nothing more the doctors can do for you', I told him simply. That such is the medical reality. He was crying and I was too, but he said to me: 'Mom, don't be afraid, the Lord knows what to do to make it right. For me and also for you. Don't be afraid'."

\section{Making decisions about treatment together}

A few days before death, Martin (17y) made a conscious decision to refuse any further treatment and in case of complications during the transport home he asked not to be resuscitated: "And then, he made the decision, it was on Monday, he died on Thursday, and on Monday he made the decision when he returned from radiotherapy and he said that it was enough, he wanted no further treatment, no radiotherapy, he just wanted to go home. He wanted to meet friends, and if possible, go to school one last time".

\section{Talks at the time of passing}

We identified three main topics at the time of passing. Firstly, the need to say goodbye to parents, secondly mutual forgiveness, and thirdly saying 'I love you'.

Saying goodbye at the time of passing

Based on medical knowledge and open communication, Kristína (18y) knew she was suffocating. Her father, a few hours before her death, says:

"She says: 'Dad, what should I do?'. But this she was only gasping for breath. 'Should I already ask for the morphine? Should I go into a coma?' I'm telling her: 'Kristy, what do you want me to tell you? I don't know how you are even keeping up. It's not my place to tell you. You have to know'. This was one of those moments, the difficult ones... And my wife says: 'I hope you won't leave without telling good bye'. All this is life, all adds up so that you begin also with this possibility. And Kristína sat up in her bed and said: 'All of you, please come here. Mom, hold my hand, dad you hold the other. And Jožko, he was her boyfriend, you come and stand behind me'. And she says: 'Mom you always said that I shouldn't leave... So, take care', she said. "And tell me mom, what shall I tell Lord Jesus when I ascend to Heaven?' And my wife says: 'You know, tell him to...', she didn't tell her to ask for resurrection or something, '... tell him to come quickly for us. To not hesitate with his second coming'. And she says: 'I'll tell him. And I'll ask him to resurrect me'. Because she was in love. 'And you focus on your prayers and believe. And now you can call the doctor to give me that morphine...' These were her last words". 
Mutual forgiveness

Martin's (17y) father at the end of his son's life says: "That last day, in the hospital it was early evening, we were lying there, he was curled on his bed, my wife on one side, me on the other. We were talking about forgiveness. About mutual forgiveness".

Saying 'I love you'

Josef's (20) father said about the day when his son died: "I also needed to rest mentally, so I went to the forest and my wife calls me that Josef wants me to come. So, I got in the car, came home, came for him, and he liked it when someone grabbed his hand and caressed it. He says 'Daddy, I love you'. In the afternoon he downloaded a picture of such a porcelain angel and died at night."

\section{Spiritual experience}

In her words, the father of Kristína (18y) points out what the disease brings. The interview section is a few hours before death, when Kristína is aware of her impending passing: "And my wife asks: 'Kristy, and if you could live your life again, what would you change?' And she says: 'Nothing'. And my wife says: 'Not even oncology?'. And she says: 'No. I would never have been so close to Him as I'm now. If I lived a normal life'. So, these were such precious moments for us. People may say that it helps to be religious. That is a living relationship with God. There is no other way to describe it. And it got us over also that night" (when she died - authors' note).

\section{Discussion}

The approach of children and their parents to the reality of cancer and thus to the approaching potential of death evolves. In this process, parents and children evolve and seek a path to openness to each other and to themselves. It turns out that unless there is openness in communication on personal issues between parents and children from the beginning, neither parents nor children are ready to talk about the disease. Some of them tend to protect themselves from emotional pain (Geest et al, 2015, Kars et al, 2015, Smith et al, 2019). With time, some of the parents feel guilty for having concealed the fact of the disease (Kreicbergs et al, 2004). However, this fact is difficult to avoid, social networks and the internet also play an important role. Through social networks, children learn that their friends, with whom they spent time in the hospital ward, are no longer alive. In the case of obscuring and confusing information from parents, this can lead to undermining the child's confidence. This in turn leads to the truthfulness and sincerity of parents with their children. Openness and truthfulness, which are borne by mutual understanding and concern, prove optimal and children appreciate this openness (Rosenberg et al, 2016). Among other benefits of open communication, it allows stronger feeling of closeness, while allowing the adolescents to decide on further treatment and where they want to die. This finding corresponds to the results of Bell et al (2010) and Rosenberg et al. (2016).

This does not apply across the board, as pointed out by the mother of a gently surviving boy who was present at her abuse and experienced bullying. Knowing her son, she assumed that an open announcement of such news would not only hurt him even more in all difficulties, but would take away his joy for the life he had left. This is consistent with the results of another studies (Geest et al, 2015, Kars et al, 2015). We add that it is not only the mutual protection of children and parents that is needed, it is also the children's need to protect themselves from the fact of illness. We agree that the decision to talk to children about impending death depends on the individual story, culture of the family, and context. Similar findings are in the studies of Geest et al (2015) or Rosenberg et al. (2016). In all cases, maintaining and delivering hope have proved essential for both children and parents (Zelcer et al, 2010, Cataudella and Zelcer, 2012, Geest et al, 2015,).

We found that a specific category consists of moments of communication at the time of dying. Children know they are dying and they can communicate this fact to those who are with them. This experience can be experienced as an input to God. But not all children talk about passing at the time of dying. We identified three main topics in the communication between child and parent related to the time of passing: saying goodbye, mutual forgiveness and saying 'I love you'.

The presence of the disease reveals what is essential, valuable in life, and what is not. This experience may also open a spiritual dimension. All this adds to the fact that at the end of life, the child can claim that they would not change anything in the life they have lived, despite their suffering.

What united all the conversations we had, even though almost none of these people ever mentioned it at all, was love. Against the backdrop of love was the pain of the loss that parents had felt even after years. Love was the most important thing in the relationship between parents and children. As one of the parents put it, two weeks before the death of his 17-year-old son: "And when he gave me a present, because he knows I like such chocolates, he bought them in a cafeteria and gave them to me and there I say: 'you know what, the most beautiful present I want for my birthday is that you give me a manly hug'. I'll never forget this hug, as long as I live! This was the best present and nothing will top this". The presence of death opens us to closeness and authenticity, so even if a child dies, he may have the attitude that nothing would change (Gerrish, Bailey, 2020).

\section{Study limitations}

This study has several limitations. First, the number of parents in our study is relatively small for the purpose of generalization of our findings. We take into account that parental communication can vary according to the child's developmental needs, family story, and unique situation (Block, 2006).

\section{Clinical implications}

Our results suggest several starting points for the clinical practice: (1) to offer option, time and space to discuss emotions and problems of parents and their terminally ill children, (2) to inform parents about children's possible reactions, lived experience and support them, (3) to accept individual parents' decision 
572-576

to talking about death with their children and to offer experiences of other parents in a similar situation, (4) to accept spiritual dimension of experience in disease and in dying, (6) to create training programs and educations for better communication between clinicians, health-care providers and parents, (7) education for better understanding of lived experience of the child with incurable cancer and his/her parent.

\section{Conclusion}

Openness in communication between parents, close environment and children who have been diagnosed with cancer is the way. In the beginning, mutual protection often occurs. If there is a situation where mutual trust in the closest relationship is threatened due to misinformation or concealment of truth, parents and children are willing to undergo the risk of truthfulness. It also turns out that from the moment they are determined to be honest and true with themselves, this truth gives them relief and can lead to open communication about dying in the last moments of the child's life. At the same time, some parents consider the protection against negative news as justified for the entire remaining time of the child's life. Openness also includes the need for making decisions together and participation of adolescents in further treatment.

\section{References}

1. Bally JM, Duggleby W, Holtslander L et al. Keeping hope possible: a grounded theory study of the hope experience of parental caregivers who have children in treatment for cancer. Cancer Nurs 2014; 37 (5): 363-372.

2. Bell CJ, Skiles J, Pradhan K, Champion VL. End-of-life experiences in adolescents dying with cancer. Support Care Cancer 2010; 18 (7): $827-835$

3. Block SD. Psychological issues in end-of-life care. J Palliat Med 2006; 9 (3): 751-772.

4. Bogetz JF, Trowbridge A, Kingsley J, Taylor M, Rosenberg AR, Barton KS. "It's my job to love him": Parenting adolescents and young adults with advanced cancer. Pediatrics 2020; 146 (6): 1-12.

5. Cataudella DA, Zelcer S. Psychological Experience of children with brain tumors and end of life: parental perspectives. J Palliat Med 2012; 15 (11): 1191-1197.

6. Dilek DS, Özlem B. Affective experiences of the parents of children with cancer: a qualitative study. CurrpPsychol 2020; 39 (6): 2211-2220.

7. van der Geest IMM, Heuvel-Eibrink MM, Vliet LM, Pluijm SMF, Streng IC, Michiels EMC, Pieters R, Darlington ASE. Talking about death with children with incurable cancer: perspectives from parents. J Pediatrics 2015; 167 (6): 1320-1326.

8. Gerrish NJ, Bailey S. Maternal Grief: A Qualitative Investigation of Mothers' Responses to the Death of a Child from Cancer. J Death Dying 2020; 81 (2): 197-241.

9. Hinds PS, Drew D, Oakes LL et al. End-of-life care preferences of pediatric patients with cancer. J Clin Oncol 2005; 23 (36): 9146-9154.
10. Kars MC, Grypdonck MHF, de Korte Verhoef MC et al. Parental experience at the end-of-life in children with cancer: 'preservation' and 'letting go' in relation to loss. Support Care Cancer 2011; 19: 27-35.

11. Kars MC, Grypdonck MHF, de Bock LC, van Delden JJM. The parents ability to attend to the "voice of their child" with incurable cancer during the palliative phase. Health Psychol 2015; 34 (4) 446-452.

12. Keim MC, Lehmann V, Schultz EL, Winning AM, Rausch JR, Barrera M, Gilmer MJ, Murphy LK, Vannatta KA, Compas BE, Gerhardt CA. Parent-child communication and adjustment among children with advanced and non-advanced cancer in the first year following diagnosis or relapse. J Pediat Psychol 2017; 42 (8): 871-881.

13. Kreicbergs U, Valdimarsdottir U, Onelöv $\mathbf{E}$ et al. Talking about death with children who have severe malignant desease. N Engl J Med 2004; 351 (12): 1175-1186.

14. Ljungman L, Boger M, Ander $M$ et al. Impressions that last: particularly negative and positive experiences reported by parents five years after the end of child's successful cancer treatment or death. Plos One 2016; 11 (6): 1-18.

15. Miovský M. Kvalitativní př́stup a metody v psychologickém výzkumu. Praha: Grada, 2006.

16. Palmer S, Mitchell A, Thompson K, Sexton M. Unmet needs among adolescent cancer patients: a pilot study. Palliat Support Care 2007; 5 (2): $127-134$.

17. Popp JM, Conway M, Pantaleao A. Parent's experience with their child's cancer diagnosis: do hopefulness, family functioning, and perception of care matter? J Pediatr Oncol Nurs 2015; 32 (4): 253-260.

18. Rodriguez EM, Dunn MJ, Zuckerman T, Vannatta K, Gerhardt CA, Compas BE. Cancer-related sources of stress for children with cancer and their parent. J Pediat Psychol 2012; 37 (2): 185-197.

19. Rosenberg AR, Wolfe J, Wiener L, Lyon M, Feudtner CH. Ethics, Emotions, and the skills of talking about progressing disease with terminally ill adolescents. JAMA Pediatr 2016; 170 (12): 1216-1223.

20. Růžička J. Komunitní a skupinová psychoterapie v české perspektivě. Triton, 2011.

21. Smith LE, Maybach AM, Feldman A, Darling A, Akard TF, Gilmer MJ. Parent and Child Preferences and Styles of Communication about Cancer Diagnoses and Treatment. J Pediat Oncol Nursing 2019; 36 (6): 390-401.

22. Smith JA, Flowers P, Larkin P(Eds). Interpretative phenomenological analysis: Theory, method and research. Sage, 2009.

23. Smith JA, Osborn M. Interpretative phenomenological analysis. In: Smith JA (Ed) Qualitative psychology: A practical guide to research methods. Sage Publications, 2003, 51-80.

24. Wiener L, Weaver MS, Bell CJ, Sansom-Daly UM. Threading the cloak: Palliative care education for care providers of adolescents and young adults with cancer. Pediatric Critical Care 2015; 9 (5): 1-18.

25. Zelcer S, Cataudella D, Cairney AE, Bannister SL. Palliative care of children with brain tumors: a parental perspective. Arch Pediatr Adolesc Med 2010; 164 (3): 225-230.

Received February 9, 2021. Accepted March 3, 2021. 